\title{
Comparison Between Eicosapentaenoic and Docosahexaenoic Acids in Terms of Essential Fatty Acid Efficacy in Larval Red Seabream*1
}

\author{
Takeshi Watanabe, ${ }^{* 2}$ Maria S. Izquierdo, ${ }^{* 2,3}$ Toshio Takeuchi, ${ }^{* 2}$ \\ Shuichi Satoh, ${ }^{* 2}$ and Chikara Kitajima** \\ (Received April 24, 1989)
}

\begin{abstract}
Efficacy of EPA and DHA as the EFA for larval red seabream was evaluated by feeding them rotifers enriched with respectively methyl oleate, EPA, DHA and n-3 HUFA mixture for 8 days in $100 /$ tanks.

The larvae fed on rotifers containing a low percentage of n-3 HUFA showed low growth and survival rates together with a high incidence of the so-called hydrops. These larvae also showed poor vitality and all of them died in the both vitality tests. The growth and survival rates were effectively improved by the incorporation of EPA and DHA or n-3 HUFA mixture into the rotifers. However, the incidence of hydrops was not completely prevented by EPA and the n-3 HUFA mixture, but was almost totally prevented by DHA. The growth and the survival rate after vitality test were also highest in the larvae fed the DHA-rotifer.

The fatty acid analysis on the total lipids of larvae has shown that the level of assimilation of DHA was much higher than EPA, although EPA may partly be converted to $22: 5 n-3$ and that no retroconversion of DHA may be available. Thus DHA is found to be superior to EPA as EFA for larval red seabream.
\end{abstract}

Recent investigations ${ }^{1.2}$ on essential fatty acids (EFA) of fish have demonstrated that marine species of finfish require $n-3$ highly unsaturated fatty acids (n-3 HUFA) such as eicosapentaenoic acid (20:5n-3, EPA) and docosahexaenoic acid (22: 6n-3, DHA) as EFA for their normal growth. The requirements of $n-3$ HUFA is about $0.5 \%$ for both juvenile ${ }^{3)}$ and larval ${ }^{4)}$ red seabream, $2.0 \%$ for juvenile yellowtail, ${ }^{5)} 0.8 \%$ for turbot, ${ }^{6)}$ about $2.0 \%$ for flounder, ${ }^{, 3}$ and around $1.8 \%$ for juvenile striped jack. ${ }^{8)}$ However, these requirements were all determined using lipids or methyl esters containing both EPA and DHA as n-3 HUFA, providing no information as to which fatty acid, EPA or DHA, is more important in various physiological functions. In rainbow trout, there is no difference in EFA efficiency between EPA and DHA, but growth and feed efficiency are enhanced by combining both fatty acids. ${ }^{n)}$ In juvenile red seabream, the EFA value of EPA is reported to be almost the same as a n-3 HUFA mixture con- taining both EPA and DHA. ${ }^{10}$ In freshwater species in which linolenic acid $(18: 3 n-3)$ is converted to DHA via EPA, EPA may not vary so much from DHA in EFA efficacy but may vary in marine fish species in which the conversion for EPA to DHA is very limited. ${ }^{1)}$ This is also supported by the fact that DHA which is usually high in the eggs of marine fish species is quickly reduced during larval development, ${ }^{11}$ although it is unknown whether or not DHA is utilized as energy during development or converted to other physiologically important substances such as prostaglandin.

Following the previous experiment ${ }^{4)}$ in which the requirement of larval red seabream for $n-3$ HUFA was determined by feeding them rotifers containing different levels of n-3 HUFA, this study was conducted to compare the dietary value in larval red seabream of EPA with DHA using rotifers enriched with EPA or DHA.

*1 Oral presentation at the Annual Meeting of the Japanese Society of Scientific Fisheries, Tokyo, April, 1988, p. 250.

*: Department of Aquatic Biosciences, Tokyo University of Fisheries, Konan, Minato, Tokyo 108, Japan (波辺 武, M.S. Izquierdo, 竹内俊郎, 佐藤秀一：東京水産大学资源育成学科).

* Present address: Department of Fisiologia Animal, Faculty of Biologia, La Laguna University, 38271 La Laguna, Tenerife, Spain.

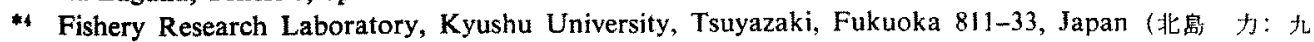
州大学農学部附属水産鉷験所)。 


\section{Materials and Methods}

\section{Preparation of Emulsified Lipids}

Four types of lipids were prepared by using methyl esters of oleic acid (18: 1n-9), EPA, DHA and n-3 HUFA mixture, as shown in Table 1 . Namely, 88\% 18: 1n-9 (Tank no. 1), 67\% EPA by mixing $18: 1 \mathrm{n}-9$ and EPA (Tank no. 2), $67 \%$ DHA by mixing 18: 1n-9 and DHA (Tank no. 3), and $85 \% \mathrm{n}-3$ HUFA containing $37 \%$ EPA and $42 \%$ DHA (Tabk no. 4). The purity of $18: 1 \mathrm{n}-9$ and DHA purchased from Sigma Chemical Co., Ltd. was $88 \%$ and $90 \%$, respectively. EPA was prepared from cuttlefish oil using vacuum distillation, ${ }^{0)}$ its purity was $85 \%$. Each lipid was homogenized with soybean lecithin (5\% in lipid) for 2-3 min by a cooled juice mixer to obtain an emulsion. ${ }^{12)}$ Emulsions were prepared each time just before enrichment of rotifers. The homogeneous condition of the emulsion was checked by a microscope.

\section{Enrichment of Rotifers}

Rotifers Brachionus plicatilis containing differnt types of fatty acids were prepared by the direct method ${ }^{12}$ ) using the above mentioned four types of lipids. Rotifers which had been fed on baker's yeast Saccharomyces cerevisiae for 7 days in one-ton polycarbonate tanks were transfered to $5 l$ tanks (with $4 l$ water) at an initial density of 200 indiv. $/ \mathrm{m} l$, and $5 \mathrm{~m} l$ of each emulsified lipid were added to each tank for enrichment. Enrichment was conducted for $12 \mathrm{~h}$ at a water temperature of 19.5-20.0 $0^{\circ} \mathrm{C}$ with vigorous aeration. Rotifers were collected once before the initiation of feeding, and twice during 8 days of feeding for analysis of lipid classes and fatty acid composition. They were filtered, and washed with running tapwater and kept at $-20^{\circ} \mathrm{C}$ until analysis. ${ }^{13}$ )

\section{Larval Rearing}

Eggs of red seabream Pagrus major, obtained from the broodstock which had been fed a commercial red seabream diet and fresh raw fish were hatched and fed on rotifers cultured with baker's yeast for 3 days at the Aquaculture Research Laboratory, Nagasaki Prefectural Institute of Fisheries. The larvae were then randomly divided into 4 groups of 2,000 fish each and fed on one of the varieties of enriched rotifers for 8 days in $100 l$ tanks. The initial total length of the larvae was $3.91 \pm 0.20 \mathrm{~mm}$. Water temperature ranged from 19.0 to $21.5^{\circ} \mathrm{C}$ during the experimental period. The rates of aeration and sea water supply were 100 and $120 \mathrm{~m} / / \mathrm{min}$, respectively. The number of rotifers given to each larval tank was $2 \times 10^{6}$ indiv./day (given twice per day, each time $1 \times$ $10^{8}$ rotifers).

At the end of the feeding trial, the so-called vitality test was conducted twice to check the fish's response to the stress. In the first and second tests 50 larvae were taken out of the water and held in the air by a scoop net for 5 and $10 \mathrm{~s}$, respectively, and moved to $30 l$ tanks to check their survival after $24 \mathrm{~h}$. The total body length of 30 individual fish larvae was measured at the initiation and termination of the experiment. The remainder of the fish were sampled and analysed for lipid classes and fatty acid composition. The details of fish care, feeding and analytical procedures have all been described in previous papers., ${ }^{4}$ )

\section{Results and Discussion}

\section{Lipid Classes and Fatty Acid Compositions of Enriched Rotifers}

Lipid classes of rotifers enriched with the various emulsions containing respectively $18: 1$, EPA, DHA and n-3 HUFA mixtures are shown in Table 2. The lipid content was the highest in the rotifers enriched with the n-3 HUFA mixture, being reflcted by the elevated levels of each lipid class. The EFA-deficient rotifers enriched with 18: 1 were lower in proportion of polar lipids and free fatty acids.

The fatty acid composition of the total lipids from rotifers fed on various lipids is listed in Table 3. The values in the table are the averages

Table 1. Composition of the experimental oils used for preparation of emulsified lipids to feed rotifers

\begin{tabular}{lcccc}
\hline & \multicolumn{4}{c}{ Tank no. } \\
\cline { 2 - 5 } & 1 & 2 & 3 & 4 \\
\hline Type of oil* & OAME & EPA+OAME & DHA + OAME & ME 85 \\
HUFA in oil $(\%)$ & 0 & 67 & 67 & 85 \\
\hline
\end{tabular}

* Abbreviations: OAME; methyl oleate, EPA; methyl eicosapentaenoate, DHA; methyl docosahexaenoate, ME 85; methyl esters $n-3$ HUFA. 
Table 2. Lipid classes in total lipids of rotifers (\%)

\begin{tabular}{|c|c|c|c|c|c|c|c|c|}
\hline \multirow{2}{*}{$\begin{array}{c}\text { Tank } \\
\text { no. }\end{array}$} & \multirow{2}{*}{ Moisture } & \multicolumn{2}{|c|}{ Crude lipid } & \multicolumn{5}{|c|}{ in Rotifers* } \\
\hline & & wet basis & dry basis & CE & TG & FFA & $\mathrm{DG}$ & PI \\
\hline 1 & 88.8 & 2.0 & 17.8 & 0.43 & 6.68 & 0.46 & 0.27 & 9.95 \\
\hline 2 & 87.7 & 2.5 & 19.8 & 0.56 & 4.39 & 2.62 & 0.36 & 11.93 \\
\hline 3 & 89.6 & 1.9 & 17.8 & 0.46 & 4.04 & 1.19 & 0.28 & 11.80 \\
\hline 4 & 88.0 & 2.8 & 23.7 & 0.64 & 5.56 & 4.31 & 0.47 & 12.66 \\
\hline
\end{tabular}

* Abbreviations: CE; cholesterol esters, TG; triglycerides, FFA; free fatty acids, DG; diglycerides, PL; polar lipids.

three determinations on the rotifers collected before and during the feeding experiment as described above. There was no marked difference between the three determinations, thus the standard deviation was deleted from each value for simplification. Thus, the larvae of each group were found to have received rotifers with almost the same fatty acid composition during the feeding period of 8 days.

The rotifers enriched with $18: 1 \mathrm{n}-9$ were signifcantly higher in the percentage of monoethylenic fatty acids, especially high in 18:1 directly affected by the methyl oleate added to the culture medium. Therefore, they were exactly the EFAdeficient rotifers containing little n-3 HUFA. The proportion of monoethylenic fatty acids was low in rotifers fed on EPA, DHA and the n-3 HUFA mixture. The rotifers enriched with the emulsion containing $67 \%$ of EPA contained $22.3 \%$ EPA and $2.3 \%$ DHA in fatty acid composition $(0.48 \%$ EPA and $0.05 \%$ DHA on a wet basis of rotifers). While those enriched with the same concentration of DHA contained $3.9 \% \mathrm{EPA}$ and $21.8 \% \mathrm{DHA}$ ( $0.06 \%$ EPA and $0.45 \%$ DHA on a wet basis). It was therefore found that two types of rotifers containing either EPA or DHA at almost the same level were successfully cultured during the period of feeding. On the other hand, both the fatty acids, EPA and DHA, were high in the rotifers fed on the emulsion containing the $n-3$ HUFA mixture. The percentages of EPA and DHA were $11.4 \%$ and $20.5 \%(0.28 \% \mathrm{EPA}$ and $0.51 \%$ DHA on a wet basis), and the total amount of $n-3$ HUFA was the highest in these rotifers, as shown in Table 2. The concentration of n-3 HUFA in each group of rotifers except those fed on methyl oleate was enough to satisfy the EFA requirement of larval red seabream.4) A relatively high percentage of $18: 2 \mathrm{n}-6$ in each rotifer must be due to the preliminary feeding of the rich in this fatty acid and 18:2n-6 contained in methyl oleate as the contamination.
Table 3. Fatty acid composition of total lipids in rotifers enriched with various lipids (area \%)

\begin{tabular}{|c|c|c|c|c|}
\hline \multirow{2}{*}{ Fatty acid } & \multicolumn{4}{|c|}{ Tank no. } \\
\hline & 1 & 2 & 3 & 4 \\
\hline $14: 0$ & 2.2 & 0.9 & 1.3 & 1.1 \\
\hline $14: 1$ & 1.1 & 0.9 & 1.2 & 0.8 \\
\hline $15: 0$ & 0.3 & 0.2 & 0.3 & 0.3 \\
\hline $16: 0$ & 5.0 & 3.6 & 4.5 & 3.9 \\
\hline $16: \ln -7$ & 10.5 & 7.4 & 8.8 & 7.2 \\
\hline $16: \ln -5$ & 0.4 & 0.2 & 0.3 & 0.3 \\
\hline $17: 0$ & 0.7 & 0.7 & 0.5 & 0.4 \\
\hline $16: 3 n-6$ & 1.2 & 0.7 & 0.9 & 0.7 \\
\hline $16: 4 n-3$ & 0.5 & 2.0 & 2.5 & 0.5 \\
\hline $18: 0$ & 2.1 & 1.2 & 1.2 & 1.9 \\
\hline $18: \ln -9$ & 51.0 & 15.1 & 25.7 & 21.8 \\
\hline $18: \ln -7$ & 7.0 & 2.7 & 4.1 & 3.7 \\
\hline $18: \ln -5$ & 1.2 & 0.5 & 0.3 & 0.2 \\
\hline $18: 2 n-6$ & 6.7 & 5.9 & 5.1 & 4.7 \\
\hline $18: 3 n-6$ & 0.7 & 0.6 & 0.4 & 0.4 \\
\hline $19: 0$ & 0.2 & 0.4 & 0.2 & ND \\
\hline $18: 3 n-3$ & 0.6 & 1.6 & 1.5 & 0.8 \\
\hline $18: 4 n-3$ & 0.2 & 2.0 & 0.2 & 0.9 \\
\hline $20: 0$ & 0.1 & 0.0 & 0.1 & 0.0 \\
\hline $20: 1 \mathrm{n}-11$ & 0.5 & 0.1 & ND & 0.5 \\
\hline $20: 1 n-9$ & 1.3 & 0.8 & 1.5 & 1.2 \\
\hline $20: 2 n-9$ & 0.3 & 0.3 & 0.4 & 0.3 \\
\hline $20: 2 n-6$ & 0.4 & 0.3 & 0.3 & 0.4 \\
\hline $20: 3 n-6$ & 0.2 & 0.8 & 0.3 & 0.3 \\
\hline $20: 4 n-6$ & 0.3 & 6.6 & 0.9 & 1.1 \\
\hline $20: 3 n-3$ & 0.1 & 0.2 & 0.1 & 0.1 \\
\hline $20: 4 n-3$ & 0.1 & 2.2 & 0.5 & 1.1 \\
\hline $20: 5 n-3$ & 0.5 & 22.3 & 3.9 & 11.4 \\
\hline $22: 0$ & ND & 0.7 & 0.4 & 0.2 \\
\hline $22: 1 \mathrm{n}-(13+11)$ & 1.8 & 3.7 & 0.4 & 1.2 \\
\hline $22: 5 n-6$ & 0.3 & 0.1 & 0.1 & 0.3 \\
\hline $22: 4 n-3$ & 0.4 & ND & 0.4 & ND \\
\hline $22: 5 n-3$ & 0.2 & 0.7 & 0.1 & 2.2 \\
\hline $22: 6 n-3$ & 0.9 & 2.3 & 21.8 & 20.5 \\
\hline $\begin{array}{l}\sum \mathrm{n}-3 \text { HUFA } \\
\mathrm{n}-3 \text { HUFA }\end{array}$ & 2.1 & 27.7 & 26.7 & 35.2 \\
\hline $\begin{array}{l}\text { in rotifers } \\
\text { (dry basis) }\end{array}$ & 0.32 & 4.65 & 4.02 & 7.05 \\
\hline
\end{tabular}


Table 4. Growth, vitality test, survival and incidence of hydrops in larval red seabream after 8 days of feeding

\begin{tabular}{|c|c|c|c|c|}
\hline & \multicolumn{4}{|c|}{ Tank no. } \\
\hline & 1 & 2 & 3 & 4 \\
\hline Type of oil* & OAME & $\mathrm{EPA}+\mathrm{OAME}$ & $\mathrm{DHA}+\mathrm{OAME}$ & ME 85 \\
\hline n-3 HUFA in rotifers (dry basis) & 0.32 & 4.65 & 4.02 & 7.05 \\
\hline \multicolumn{5}{|l|}{ Total length $(\mathrm{mm})$} \\
\hline Average & 4.40 & 4.69 & 4.98 & 4.71 \\
\hline SD & 0.27 & 0.32 & 0.61 & 0.33 \\
\hline \multicolumn{5}{|l|}{ Survival after vitality test $(\%)$} \\
\hline Test I ( $5 \mathrm{~s})$ & 0 & 6 & 63 & 7 \\
\hline Test II (10 s) & 0 & 17 & 52 & 29 \\
\hline Survival rate $(\%)$ & 32 & 59 & 57 & 53 \\
\hline Hydrops incidence $(\%)$ & 47 & 21 & 7 & 20 \\
\hline
\end{tabular}

* See the footnote of Table 1 .

\section{Growth of Larvae Fed Enriched Rotifers}

Results of feeding of larvae on rotifers with various treatments are shown in Table 4 and Fig. 1. As usually observed in larvae fed on yeast-fed rotifers, ${ }^{14)}$ feeding the EFA-deficient rotifers to larvae resulted in the lowest growth and survival together with a high percentage of fish with the socalled hydrops which was firstly described in larval red seabream by Yamashita. ${ }^{15)}$ These EFA-deficient larvae were also poor in vitality and all of them died in the both vitality tests. The growth and survival rates were effectively improved by incorportaion of EPA and DHA or n-3 HUFA mixture, together with a reduction of the hydrops incidence. However, the occurrence of hydrops was not completely prevented by incorporation of EPA or n-3 HUFA mixture, but almost totally prevented by DHA. The growth and survival rates in the vitality test were also the highest in the larvae fed the DHA-rotifers. The dietary value for larval red seabream of rotifers containing DHA as a main n-3 HUFA was therefore found to be higher than those containing EPA as the main n-3 HUFA. Rotifers fed on n-3 HUFA mixture containing both EPA and DHA contained almost the same level of DHA as the DHA-rotifers, but their dietary value was poorer than that of the DHA-rotifers. This may partly be due to the ill effect of the $n-3$ HUFA methyl esters on both rotifers and larval red seabream.* The proportion of DHA to EPA may also be important for larval red seabream.

The result that DHA is superior to EPA as EFA for larval red seabream suggests that enrichment
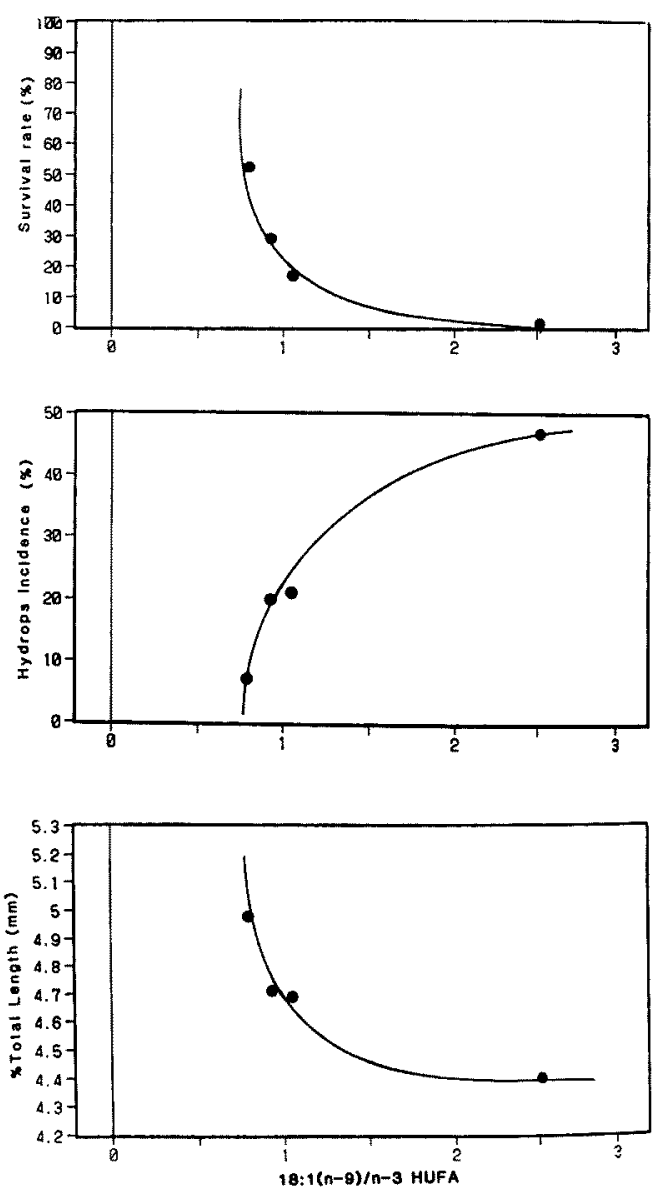

Fig. 1. Relationship between the 18: 1n-9/n-3 HUFA ratio in total lipids and growth, survival and incidence of hydrops in larval red seabream.

* M. S. Izquierdo, T. Takeuchi, T. Arakawa, C. Kitajima, and T. Watanabe: Abstracts of the annual meeting of the Japan. Soc. Sci. Fish., Tokyo, April, 1988, p. 250. 
Table 5. Lipid classes of total lipids in larval red seabream fed the various enriched rotifers (wet basis) $(\%)$

\begin{tabular}{ccccccc}
\hline \hline \multirow{2}{*}{$\begin{array}{c}\text { Tank } \\
\text { no. }\end{array}$} & $\begin{array}{c}\text { Crude } \\
\text { lipid }\end{array}$ & CE & TG & FFA & FS* & PL \\
\cline { 3 - 7 } & & 0.01 & 0.03 & 0.10 & 0.37 & 1.57 \\
\hline Initial & 2.1 & ND & 0.11 & 0.15 & 0.13 & 1.99 \\
1 & 2.4 & ND & 0.05 & 0.07 & 0.30 & 1.99 \\
2 & 2.4 & ND & 0.05 & 0.17 & 0.26 & 2.10 \\
3 & 2.5 & 0.05 & 0.10 & 0.31 & 0.49 & 2.57 \\
4 & 3.5 & & 0.05 & & &
\end{tabular}

* See the footnote of Table 2. FS; free sterols.

Table 6. Fatty acid composition of total lipids in larval red seabream (area \%)

\begin{tabular}{|c|c|c|c|c|c|}
\hline \multirow{2}{*}{ Fatty acid } & \multirow{2}{*}{ Initial } & \multicolumn{4}{|c|}{ Tank no. } \\
\hline & & 1 & 2 & 3 & 4 \\
\hline $14: 0$ & 1.3 & 2.2 & 1.8 & 1.6 & 4.0 \\
\hline $14: 1$ & 0.5 & 0.6 & 0.4 & 0.4 & 0.9 \\
\hline $15: 0$ & 0.6 & 0.8 & 1.1 & 1.0 & 2.1 \\
\hline $16: 0$ & 16.4 & 13.2 & 15.3 & 15.5 & 17.7 \\
\hline $16: \ln -7$ & 9.3 & 8.7 & 8.0 & 5.9 & 7.9 \\
\hline $16: \ln -5$ & 0.3 & 0.2 & 1.6 & 0.7 & 0.2 \\
\hline $17: 0$ & 1.3 & 1.4 & 1.9 & 1.5 & 1.7 \\
\hline $16: 3 n-6$ & 1.0 & 1.2 & 1.0 & 1.0 & 0.8 \\
\hline $16: 4 n-3$ & 0.5 & 0.7 & 0.8 & 0.3 & 0.8 \\
\hline $18: 0$ & 9.3 & 5.5 & 9.5 & 9.4 & 7.6 \\
\hline $18: \ln -9$ & 20.3 & 30.7 & 18.9 & 20.1 & 17.0 \\
\hline $18: 1 \mathrm{n}-7$ & 0.1 & ND & ND & ND & ND \\
\hline $18: 2 n-9$ & 1.7 & ND & ND & 0.8 & ND \\
\hline $18: 2 n-6$ & 4.8 & 10.0 & 6.5 & 5.2 & 3.8 \\
\hline $18: 3 n-6$ & 0.6 & 0.2 & 0.1 & 0.2 & 0.2 \\
\hline $18: 3 n-3$ & 0.2 & 0.3 & 0.5 & 0.4 & 0.2 \\
\hline $18: 4 n-3$ & 0.1 & 0.1 & 0.3 & ND & 0.2 \\
\hline $20: 0$ & 0.2 & 0.1 & 1.1 & 0.1 & 0.2 \\
\hline $20: \ln -(11+9)$ & 2.1 & 1.3 & 1.7 & 0.1 & 1.5 \\
\hline $20: 2 n-9$ & 0.5 & 0.4 & 0.1 & 0.2 & 0.1 \\
\hline $20: 2 n-6$ & 0.4 & 0.8 & 0.3 & 0.6 & 0.3 \\
\hline $20: 3 n-9$ & 0.3 & 0.4 & 0.2 & 0.3 & 0.2 \\
\hline $20: 4 n-6$ & 2.7 & 2.0 & 5.5 & 2.0 & 1.6 \\
\hline $20: 3 n-3$ & 0.2 & 0.6 & 0.3 & 0.2 & 0.2 \\
\hline $20: 4 n-3$ & 0.4 & 0.3 & 1.0 & 0.3 & 0.5 \\
\hline $20: 5 n-3$ & 5.2 & 2.9 & 9.1 & 3.1 & 4.4 \\
\hline 22:0 & ND & ND & 0.1 & ND & 0.1 \\
\hline $22: \ln -(13+11)$ & 1) 0.2 & ND & 1.4 & ND & 0.1 \\
\hline $22: 5 n-6$ & 0.1 & ND & ND & ND & ND \\
\hline $22: 4 n-3$ & $\mathrm{ND}$ & 0.2 & ND & ND & ND \\
\hline $22: 5 n-3$ & 4.0 & 1.5 & 2.2 & 0.9 & 1.6 \\
\hline $22: 6 n-3$ & 11.0 & 6.8 & 5.5 & 20.4 & 11.5 \\
\hline$\sum$ n-3 HUFA & 20.8 & 12.2 & 18.0 & 25.0 & 18.2 \\
\hline$\frac{18: 1 \mathrm{n}-9}{\mathrm{n}-3 \text { HUFA }}$ & 0.98 & 2.52 & 1.05 & 0.80 & 0.93 \\
\hline $\begin{array}{l}\text { n-3 HUFA in } \\
\text { fish (wet basis) }\end{array}$ & 0.38 & 0.26 & 0.39 & 0.56 & 0.58 \\
\hline
\end{tabular}

of rotifers with fish oil rich in DHA is very effective for improvement of the dietary value of the Chlorella-fed rotifers which are usually high in EPA, but very low in DHA.

\section{Lipid Classes and Fatty Acid Compositions of Larvae}

Lipid classes of larvae fed rotifers with various treatments are shown in Table 5. The lipid content of larvae was the highest in those fed the $n-3$ HUFA-rotifers and the lowest in those fed the EFA-deficient rotifers, clearly reflected by the lipid content of rotifers. The content of polar lipids was also the highest in the former larvae and the lowest in the latter.

The fatty acid distribution of the total lipids of larvae is shown in Table 6. In the larvae fed the EFA-deficient rotifers the percentage of $18: 1 \mathrm{n}-9$ was elevated to $30.7 \%$ from the initial value of $20.3 \%$ during 8 days of feeding and that of EPA and DHA decreased to $2.9 \%$ and $6.8 \%$ from $5.2 \%$ and $11.0 \%$, respectively. The $22: 5 n-3$ level was also reduced from $4.0 \%$ to $1.5 \%$ in these fish. Consequently, the ratio between $18: 1 \mathrm{n}-9$ and $n-3$ HUFA (one of the EFA indices for juvenile red seabream proposed by Fujii et $a l^{33}$ ) increased to 2.52 from the original value of 0.98 . In the fish fed the EPA-rotifers the proportion of EPA increasesd, but that of DHA decreased to almost one half the initial concentration. The percentage of 22: $5 n-3$ was the highest in the larvae fed on EPA, suggesting the conversion of EPA to 22:5n-3. Feeding the DHA-rotifers resulted in an increase of DHA which was almost double the initial value. The EFA index was the lowest in this group. The level of assimilation of DHA was higher than EPA, although EPA may partly be converted to $22: 5 n-3$ and no retroconversion of DHA may be available. This difference in tissue accumulation between EPA and DHA may partly be responsible for the difference in dietary value between these fatty acids. 
This may also be supported by the results obtained in the larvae fed the n-3 HUFA-rotifers. In these larvae the percentage of EPA and DHA was $4.4 \%$ and $11.5 \%$, almost the same levels as the original values, in spite of the fact that the rotifers fed to the larvae contained almost the same level of DHA as the DHA-rotifers. The low level of assimilation of EPA and/or DHA in the n-3 HUFA mixture may be attributable to the difference in growth and survival of larval red seabream.

The similar results suggesting that DHA is superior to EPA as EFA has also been reported in juvenile red seabream*1 and juvenile striped jack.*2 The concentration of DHA is usually high in eggs of both species and is quickly decreased during larval development, suggesting that DHA is selectively utilyzed as energy for tissue development or converted to physiologically important derivatives such as prostaglandins. Further experiments will be necessary to clarify these points and the differences in physiological functions between EPA and DHA in various fish species.

\section{Acknowledgements}

We express here our sincere thanks to Dr. Brian Davy, IDRC, Canada who kindly read the manuscript and gave valuable suggestions. Thanks also extended to Mr. Toshihisa Arakawa, Aquaculture Research Laboratory, Nagasaki Prefectural Institute of Fisheries, for his assistance.

\section{References}

1) T. Watanabe: Comp. Biochem. Physiol, 73B, 3-15 (1982).

2) A. Kanazawa: In "Nutrition and Feeding in Fish" (ed. by C. B. Cowey, A. M. Mackie, and J. G. Bell), Academic Press, London, 1985, pp. 281-298.

3) M. Fujii, H. Nakayama, and Y. Yone: Rep. Fish. Res. Lab. Kyushu University, 3, 65-86 (1976).

4) M. S. Izquierdo, T. Watanabe, T. Takeuchi, T. Arakawa, and C. Kitajima: Nippon Suisan Gakkaishi, 55, 859-867 (1989).

5) O. Deshimaru: Feed Oil Abstr., No. 20, 1-7 (1984).

6) F. J. Gatesoupe, C. Leger, R. Metailler, and P. Luquet: Ann. Hydrobiol., 8, $89-97$ (1977).

7) A. Kanazawa: Saibaigiken, 14, 87-96 (1985).

8) T. Watanabe, T. Takeuchi, T. Arakawa, K. Imaizumi, S. Sekiya, and C. Kitajima: Nippon Suisan Gakkaishi, 55, 1111-1117 (1989).

9) T. Takeuchi and T. Watanabe: Nippon Suisan Gakkaishi, 43, 947-953 (1977).

10) Y. Yone: In "Dietary Lipids in Aquaculture" (ed. by Japan. Soc. Sci. Fish.), Koseisha-Koseikaku, Tokyo, 1978, pp. 43-59.

11) T. Watanabe: In "Dietary Lipids in Aquaculture" (ed. by Japan. Soc. Sci. Fish.), KoseishaKoseikaku, Tokyo, 1978, pp. 92-111.

12) T. Watanabe, T. Tamiya, A. Oka, M. Hirata, C. Kitajima, and S. Fujita: Nippon Suisan Gakkaishi, 49, 471-479 (1983).

13) T. Watanabe, T. Arakawa, C. Kitajima, K. Fukusho, and S. Fujita: Nippon Suisan Gakkaishi, 44, 979-984 (1978).

14) T. Watanabe, F. Oowa, C. Kitajima, and S. Fujita: Nippon Suisan Gakkaishi, 46, 35-41 (1980).

15) K. Yamashita: Jpn. J. Icthyology, 28, 80-85 (1981).

*1 T. Watanabe, T. Takeuchi, M. Toyota, T. Arakawa, and M. Yoshida: Abstracts of the annual meeting of the Japan. Soc. Sci. Fish., Tokyo, April. 1989, p. 39.

*: T. Watanabe, T. Takeuchi, T. Arakawa, M. Yoshida, and T. Fujiki: Abstracts of the annual meeting of the Japan. Soc. Sci. Fish., Shimizu, October, 1988, p. 74.

Nippon Suisan Gakkaishi : Formerly Bull. Japan. Soc. Sci. Fish. 